\title{
Modeling and analysis of a mistuned fan blisk
}

\author{
Muhammad Usman Bashir****, Anees Ur Rehman*, Aashir Waleed***, Umar Siddique Virk* \\ and Muhammad Rameez Javed**** \\ * Mechanical, Mechatronics and Control Engineering, University of Engineering and Technology, Lahore, Punjab, Pakistan. \\ *** Electrical, Electronics and Telecommunication Engineering, University of Engineering and Technology, Lahore (Faisalabad Campus), \\ Faisalabad, Punjab, Pakistan. \\ **** School of Electrical Engineering, Southeast University, Xuanwu District, Nanjing, Jiangsu Province, Peoples Republic of China. \\ **Corresponding Author: usman.bashir.mch@gmail.com
}

$\begin{array}{ll}\text { Submitted } & : 08 / 07 / 2020 \\ \text { Revised } & : 06 / 07 / 2021 \\ \text { Accepted } & : 03 / 08 / 2021\end{array}$

\begin{abstract}
Turbomachinery has a vital role in the industrial engineering and the bladed disks, such as compressor, impeller pumps, turbine generator, and jet engines, are the critical components of turbomachinery. This work is focused on the "mistuning effect" of bladed disks of a turbine, which creates the lack of symmetry and ultimately damages the turbine blade. In order to completely understand the severity of the damage caused by the mistuning effect on the turbine disk, the study and analysis of the model parameters are very important. This work provides an insight to the various effects caused by the presence of crack and mistuning levels, in the mistuned turbine blisk, by using smeared material properties and modal assurance criterion (MAC) techniques. Moreover, a mistuned blisk model with four cracks (at various locations and different depth levels) has been developed and compared with the tuned blisk model, in order to determine the severity of damage occurred. The MAC results indicate that the severity of damage may vary depending on the location and depth of the crack, and mistuning may alter the dynamic and vibrational characteristics of the structure.
\end{abstract}

Keywords: MAC (modal assurance criterion); Crack location; Blisk; Natural frequency; Damage index (DI).

\section{INTRODUCTION}

In order to avoid catastrophic failure of the turbo machines at early stages, the turbine blades must be examined periodically in order to detect irregular vibrations and cracks in the structure (Bouzid et al., 2015). Therefore, the condition monitoring is an integral part of the turbomachines because the dynamic analysis of the structure is more concerned factor in terms of modelling the cracked blades (Abboud, Elbadaoui, and Tableau, 2021) (Yule et al., 2021). In mechanics, it is assumed that the structures are perfectly symmetric. But under repeated loading conditions, the certain elements of the structure bear a loss of stiffness (Altunışı et al., 2019) (Beck et al., 2014), which may lead to the loss of symmetry. The loss of symmetry in the repeating structures is called mistuning (Schwerdt, Panning-von Scheidt, and Wallaschek, 2021) (Figaschewsky and Kühhorn, 2015), and this can increase the stress level and can reduce the fatigue life of the disks (Dréau et al., 2021) (Repetckii, Ryzhikov, and Nguyen, 2018). 
Normally, the damage or crack presence in the structure reduces the stiffness of a structure locally, which may alter the vibrational characteristics of the structure. That's why, it is very important to examine the vibrational characteristics (such as model damping and natural frequency, etc.) of mistuned structures in order to completely understand the impact of mistuning (Zhong and Yang, 2016) (Nacim et al., 2015) (Mehboob, Zaman Khan, and Ahmad, 2020) (Zeidan, Beshr, and Sameh, 2020) (ERBAYRAK and Erbayrak, 2020) (Anandan, 2019) (Wang et al., 2019). Thus, the change in vibrational characteristics can be used as a tool to detect and quantify the structural damages or cracks (Zhong and Yang, 2016) (Thulasendra and Dewangan, 2017) in the structure. There are many works in the literature which have used change in vibrational characteristics for the crack detections and measuring the damage index (DI) in the structures. For instance, in the work of Carminati and Ricci, 2018, to understand the nonlinear effects in the damaged structure, nonlinear output frequency response functions (NOFRF) are compared with frequency response functions (FRFs). In addition to that, many nondestructive techniques (NTD), such as dye penetrant, radiography, ultrasonic, thermography, eddy current inspection, and so on, can also be used for detection of cracks in turbine blades. However, these methods have limited use in the turbo machines whenever they are under operation (Booysen et al., 2015).

It is worth mentioning here that the location and depth of the crack is also of critical importance, and damage index is very sensitive towards slight changes in the location and depth of crack. For that purpose, a finite element model (FEM) of the cracked structure is required in order to analyze the impact of changing crack location and crack depth within a structure. The evaluation of such cracked FEM can be obtained by using ANSYS Parametric Design Language (APDL), and the data sorting can be done by linking ANSYS with MATLAB in order to avoid the manual vector displacement. Then, the deviations in the matrices of data are obtainable using MAC codes as MAC analysis predicts effectively the impact of crack in a damaged structure. Actually, the severity of damage can be calculated by calculating change in MAC value from reference tuned model to the mistuned model. Moreover, MAC can also provide the nature and contribution of that particular set of nodes that have undergone the damage (A U Rehman, Rongong, and Worden, 2010) (A U Rehman, Worden, and Rongong, 2011) (Anees U Rehman, Worden, and Rongong, 2016). In fact, the MAC coefficient gives the correlation between two measured mode shapes as provided in Equation (1) (Rehman, Worden, and Rongong, 2016):

$$
M A C_{i j}=\frac{\left|\sum\left(\left.\emptyset_{A}\right|_{k} ^{i}\right)\left(\left.\emptyset_{B}\right|_{k} ^{j}\right)\right|^{2}}{\sum_{k=1}^{N}\left(\left.\emptyset_{A}\right|_{k} ^{i}\right)^{2} \sum_{k=1}^{N}\left(\left.\emptyset_{B}\right|_{k} ^{j}\right)^{2}}
$$

where $\emptyset_{A}$ represents $\mathrm{m}_{\mathrm{A}}$ mode measured for $\mathrm{n}$ points, $\emptyset_{B}$ represents $\mathrm{m}_{\mathrm{B}}$ mode measured for $\mathrm{n}$ points, $\left.\emptyset_{A}\right|_{k} ^{i}$ represents $\mathrm{k}^{\text {th }}$ component of the modes $\emptyset_{A}$, and $\left.\emptyset_{B}\right|_{k} ^{j}$ represents $\mathrm{k}^{\text {th }}$ component of the modes $\emptyset_{\mathrm{B}}$. The MAC coefficient can vary from 0 to 1 , where 1 means a consistent model vector and 0 stands for inconsistent model vector. The extent of damage can be represented by MAC severity which is scalar value obtained by the square rooting of the summation of square values of all individual elements as shown in Equation (2):

$$
\|A\|_{F}=\sqrt{\sum_{i=1}^{m} \sum_{j=1}^{n}\left|a_{i j}\right|^{2}}
$$

where ' $a$ ' is the matrix of solved APDL structure. This matrix is acquired from "Source Code APDL" after processing the data. The term ij in the equation represents the rows and column, respectively.

In this research work, the impact of mistuning is studied for a turbine fan blisk model by considering four different crack locations (variable depth) simultaneously one after the other. The number of crack elements for each crack location is fourteen, and smeared material properties have been used for the crack formation. The impact of location and depth of crack and its contribution in crack severity have been calculated using MAC technique by the comparison of mistuned model properties from a reference tuned model data. 


\section{RESULTS AND DISCUSSIONS}

The meshed model of a single blade without proportional rotor part of a turbine blisk is shown in Figure 1(a). In this work, the finite element model of a single blade along with its proportional disk part is defined as a sector blisk (blade and disk part) as shown in Figure 1(b). If we establish one sector blisk (blade and disk) as a single zone, then a tuned N-numbered bladed disk is said to have $\mathrm{N}$-identical zones. Such structures are said to be cyclic symmetric, and by implementing certain conditions at the interfaces of adjacent zones, a model of just one zone is sufficient to predict the vibration of entire sector. This moderation is beneficial in running the finite element analysis of tuned system, because it saves the processing time and inspection of complex data as well. A complete 3D fan blisk model specifications (chord length, twist angle, and chord width) along with the geometric, materialistic, and element properties of the blisk model is provided in Table 1.

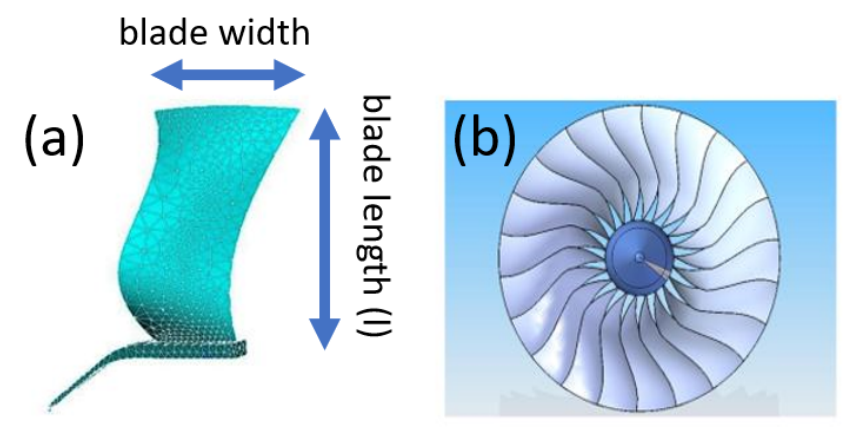

Figure 1. (a) The meshed model of single blade. (b) The sector blisk of the turbo fan.

Table 1. 3D blisk model specifications along with the geometric, material, and element properties.

\begin{tabular}{|c|c|c|}
\hline \multicolumn{3}{|c|}{ 3D fan blisk model Properties } \\
\hline \multicolumn{2}{|c|}{ Blisk Shape } & Helical \\
\hline \multicolumn{2}{|c|}{ Chord length at the base of the blade } & $405.3 \mathrm{~mm}$ \\
\hline \multicolumn{2}{|c|}{ Twist angle at the base of the blade } & Zero (parallel to rotor axis) \\
\hline \multicolumn{2}{|c|}{ Chord width at the base of the blade } & $15.05 \mathrm{~mm}$ \\
\hline Geometric Characteristics & Material Characteristics & Element Properties \\
\hline Total blades of Turbo fan $=22$ & $\begin{array}{l}\text { Modulus of Elasticity } €= \\
200 \mathrm{GPa}\left(200000 \mathrm{~N} / \mathrm{mm}^{2}\right)\end{array}$ & Element Type $=$ PLANE 183 \\
\hline $\begin{array}{c}\text { Length of Leading Edge from } \\
\text { Base }=1076.12 \mathrm{~mm}\end{array}$ & Materials $=$ Steel & $\begin{array}{c}\text { Element Shape }=\text { Quadrilateral } \\
\text { (Eight Nodes) }\end{array}$ \\
\hline $\begin{array}{l}\text { Length of Trailing Edge from } \\
\text { Base }=1033 \mathrm{~mm}\end{array}$ & Poisson Ratio $=v=0.3$ & Element Behavior $=$ Plane Stress \\
\hline $\begin{array}{l}\text { Total Number of Elements on a } \\
\text { single blisk }=2687\end{array}$ & Density $=78 \times 10^{-7} \mathrm{~kg} / \mathrm{mm}^{3}$ & $\begin{array}{c}\text { Element Formulation }=\text { Pure } \\
\text { Displacement } \\
\text { Constrained Locations }=\mathrm{x} \text {-axis } \\
\text { and radially at center }\end{array}$ \\
\hline
\end{tabular}


For the crack simulation of the model, we need to develop the finite element model of the fan blisk along with the cracks of various depth and location on the structure. The selection of crack location (CL) and crack depth (CD) is important, in order to understand the damage nature for various cracks and to locate the most sensitive areas for the crack propagation (Booysen et al., 2015) (Francis, 2013). It is worth noting that the crack initiation and its propagation in the structure also alter the dynamic characteristics of the structure along with the vibrational characteristics. The crack location and crack depth can be found by using Equation (3) and Equation (4), respectively, where the crack location is the ratio of crack edge distance from the base (b) to the total length of blade (1). Mathematically,

$$
C L=\frac{b}{l}
$$

And the crack depth (CD) is the ratio of crack length (a) to the width of blade (d):

$$
C D=\frac{a}{d}
$$

In this work, the four different smear crack locations have been introduced in the blisk model as provided: (i) crack at blade tip ( $\mathrm{b} / \mathrm{l}=0.94)$, (ii) crack at $3 / 4$ th blade length $(\mathrm{b} / \mathrm{l}=0.67)$, (iii) crack at slightly below the mid of the blade $(b / l=0.32)$, and (iv) the crack near the rotor of the blade $(b / l=0.10)$. And they are shown in Figure 2.

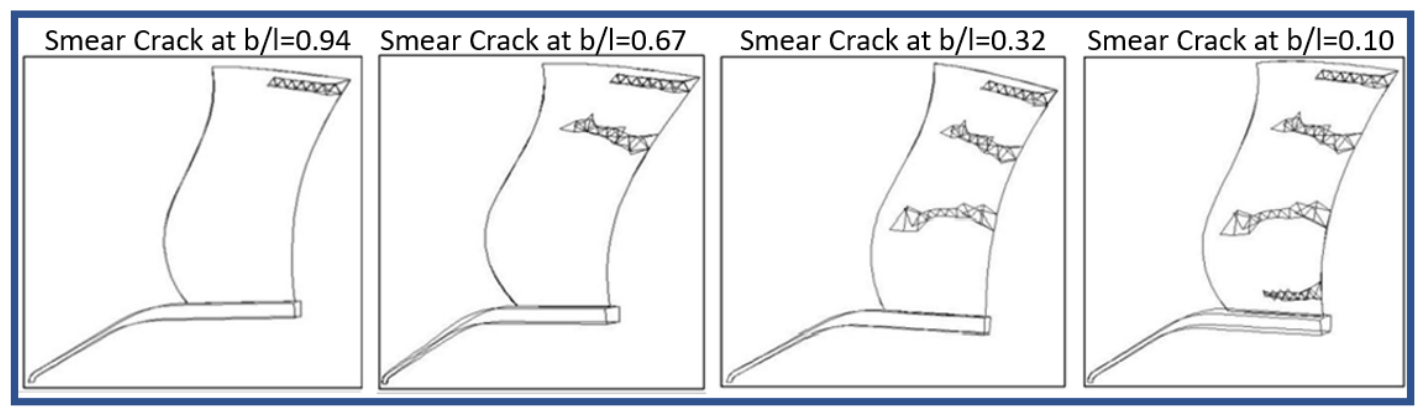

Figure 2. Different crack locations as chosen for the analysis.

A fixed number of fourteen elements have been selected for each crack location, and each crack has a varying depth from one location to the other due to the variations present in the size of meshed elements. These cracks have been simulated one after the other (starting from 1st crack location to the 4th crack location), which means the behavior of one crack location has been analyzed in the presence of previous crack location. After that, the behavior of all four crack locations is summed up, while the pattern of change in element's stiffness is kept constant at all four crack locations. The stiffness value of first element is kept small for the purpose of easy detection and is increased gradually to meet its parent material value. In this work, the fine meshing is not possible because the APDL was unable to provide the solution. So, free meshing was selected which resulted in varied element sizes. At the next stage, the MAC severity analysis is performed for each crack element of the crack location in order to obtain the value of damage due to that crack element. In MAC severity analysis, the MAC plot obtained from each crack element is subtracted from an already saved reference tuned MAC plot of the structure (called Frobenius Norm Calculation) as shown in Figure 3, for calculating the severity damage against each crack element of the crack location. 


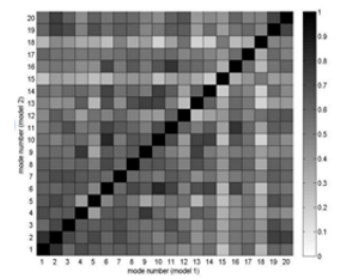

MAC plot of Reference Tuned Model

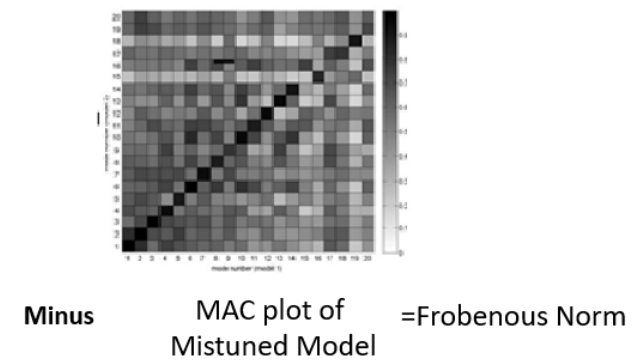

Mistuned Model $=$ Frobenous Norm

Figure 3. Frobenius Norm Calculation can be calculated by subtracting MAC plots of the mistuned and reference tuned models.

In the MAC severity analysis, all steps like data sorting and extracting the required results from vector displacement have been performed by MATLAB software. In fact, the MAC severity analysis is performed for crack assessment in the structure by calculating damage index with respect to crack location, crack depth ratio, and modulus of elasticity. The results obtained from the MAC analysis have been summarized in Tables 2-4. Table 2 presents the variations in the value of Young's modulus (E) for each crack location, and it is evident from the table that $\mathrm{E}$ is varying for each crack element and is approaching to the original material value, that is, $200 \mathrm{GPa}$ or $200000 \mathrm{~N} / \mathrm{mm} 2$. Furthermore, the value of "E" at 1st crack element for each crack location is kept low, and the value of $\mathrm{E}$ is increasing as the crack is propagating in the structure, and, thus, the DI is decreasing as the value of $\mathrm{E}$ is approaching the parent material.

Table 2. The variation of Modulus of Elasticity (E) at each crack location.

\begin{tabular}{|c|c|c|c|c|c|c|c|}
\hline \multicolumn{2}{|c|}{$\begin{array}{c}\text { Crack Location } 1^{\text {st }} \\
(\mathrm{b} / \mathrm{l}=0.94)\end{array}$} & \multicolumn{2}{c|}{$\begin{array}{c}\text { Crack Location 2 } \\
(\mathrm{b} / \mathrm{l}=0.67)\end{array}$} & \multicolumn{2}{c|}{$\begin{array}{c}\text { Crack Location } 3^{\text {rd }} \\
(\mathrm{b} / \mathrm{l}=0.32)\end{array}$} & \multicolumn{2}{c|}{$\begin{array}{c}\text { Crack Location } 4^{\text {th }} \\
(\mathrm{b} / \mathrm{l}=0.10)\end{array}$} \\
\hline $\begin{array}{c}\text { Crack Depth } \\
\text { Ratio (a/d) }\end{array}$ & $\begin{array}{c}\text { Modulus of } \\
\text { Elasticity E, } \\
\left(\mathrm{N} / \mathrm{mm}^{2}\right)\end{array}$ & $\begin{array}{c}\text { Crack Depth } \\
\text { Ratio (a/d) }\end{array}$ & $\begin{array}{c}\text { Modulus of } \\
\text { Elasticity E, } \\
\left(\mathrm{N} / \mathrm{mm}^{2}\right)\end{array}$ & $\begin{array}{c}\text { Crack Depth } \\
\text { Ratio (a/d) }\end{array}$ & $\begin{array}{c}\text { Modulus of } \\
\text { Elasticity E, } \\
\left(\mathrm{N} / \mathrm{mm}^{2}\right)\end{array}$ & $\begin{array}{c}\text { Crack Depth } \\
\text { Ratio (a/d) }\end{array}$ & $\begin{array}{c}\text { Modulus of } \\
\text { Elasticity E, } \\
\left(\mathrm{N} / \mathrm{mm}^{2}\right)\end{array}$ \\
\hline 0.0799 & 5000 & 0.0941 & 5000 & 0.1404 & 5000 & 0.0655 & 5000 \\
\hline 0.1175 & 10000 & 0.1458 & 10000 & 0.1866 & 10000 & 0.1070 & 10000 \\
\hline 0.1403 & 25000 & 0.1901 & 25000 & 0.2636 & 25000 & 0.1342 & 25000 \\
\hline 0.1746 & 50000 & 0.2477 & 50000 & 0.3030 & 50000 & 0.1738 & 50000 \\
\hline 0.1949 & 75000 & 0.2660 & 75000 & 0.2865 & 75000 & 0.2009 & 75000 \\
\hline 0.2327 & 100000 & 0.3147 & 100000 & 0.3669 & 100000 & 0.2347 & 100000 \\
\hline 0.2463 & 115000 & 0.3376 & 115000 & 0.3724 & 115000 & 0.2671 & 115000 \\
\hline 0.2844 & 130000 & 0.3755 & 130000 & 0.4342 & 130000 & 0.3098 & 130000 \\
\hline 0.2940 & 145000 & 0.3951 & 145000 & 0.4442 & 145000 & 0.3354 & 145000 \\
\hline 0.3308 & 160000 & 0.4386 & 160000 & 0.5072 & 160000 & 0.3801 & 160000 \\
\hline 0.3392 & 175000 & 0.4447 & 175000 & 0.5145 & 175000 & 0.3993 & 175000 \\
\hline 0.3751 & 190000 & 0.5109 & 190000 & 0.5739 & 190000 & 0.4348 & 190000 \\
\hline 0.3809 & 195000 & 0.5092 & 195000 & 0.6202 & 195000 & 0.4679 & 195000 \\
\hline 0.4102 & 200000 & 0.5870 & 200000 & 0.7029 & 200000 & 0.4967 & 200000 \\
\hline
\end{tabular}


Table 3 shows the frequencies (vibrational characteristics) of each crack location along with relevant crack depth ratios at an equal interval of 0.5 . This provides an insight to the frequency modes at different crack locations by providing comparison without frequency and with frequency modes. Figure 4 presents the plot between crack depth ratio (CDR) and natural frequency (NF). The insert image provides the zoomed-in comparison of the natural frequency change for variations in the CDR for all four crack locations. In this figure, the reduction of frequency at fourth crack location is observed more as compared to other crack locations because this location lies more near to rotor of the blade. Whereas, the reduction of frequency is observed slow at or near the blade tip.

Table 3. Crack depth ratio and natural frequency for different crack locations.

\begin{tabular}{|c|c|c|c|c|c|c|}
\hline $\begin{array}{l}\text { Mode } \\
\#\end{array}$ & $\begin{array}{l}\text { Crack Depth } \\
\text { Ratio }\end{array}$ & $\begin{array}{c}\text { Without Crack } \\
\text { Frequency }\end{array}$ & $\begin{array}{l}\text { 1st Location } \\
\text { Crack } \\
\text { Frequency }\end{array}$ & $\begin{array}{c}2^{\text {nd }} \text { Location } \\
\text { Crack } \\
\text { Frequency }\end{array}$ & $\begin{array}{l}3^{\text {rd }} \text { Location } \\
\text { Crack } \\
\text { Frequency }\end{array}$ & $\begin{array}{c}4^{\text {th }} \text { Location } \\
\text { Crack } \\
\text { Frequency }\end{array}$ \\
\hline 1 & 1 & 1.6558 & 1.6557 & 1.6556 & 1.6555 & 1.6554 \\
\hline 2 & 0.95 & 2.9123 & 2.9119 & 2.9115 & 2.9112 & 2.9108 \\
\hline 3 & 0.9 & 4.1807 & 4.18 & 4.1786 & 4.1775 & 4.176 \\
\hline 4 & 0.85 & 6.7536 & 6.7513 & 6.7472 & 6.7436 & 6.7387 \\
\hline 5 & 0.8 & 7.2665 & 7.2599 & 7.2513 & 7.2458 & 7.2387 \\
\hline 6 & 0.75 & 10.843 & 10.809 & 10.753 & 10.713 & 10.669 \\
\hline 7 & 0.7 & 14.029 & 14.013 & 13.984 & 13.964 & 13.942 \\
\hline 8 & 0.65 & 15.603 & 15.58 & 15.546 & 15.521 & 15.497 \\
\hline 9 & 0.6 & 16.841 & 16.823 & 16.804 & 16.793 & 16.778 \\
\hline 10 & 0.55 & 18.618 & 18.439 & 18.207 & 18.048 & 17.934 \\
\hline 11 & 0.5 & 22.513 & 22.336 & 22.144 & 22.008 & 21.94 \\
\hline 12 & 0.45 & 24.499 & 24.417 & 24.323 & 24.263 & 24.229 \\
\hline 13 & 0.4 & 26.772 & 26.655 & 26.553 & 26.486 & 26.443 \\
\hline 14 & 0.35 & 28.985 & 28.58 & 28.322 & 28.175 & 28.119 \\
\hline 15 & 0.3 & 30.546 & 30.533 & 30.524 & 30.517 & 30.509 \\
\hline 16 & 0.25 & 31.645 & 31.313 & 31.1 & 30.949 & 30.906 \\
\hline 17 & 0.2 & 32.974 & 32.889 & 32.857 & 32.84 & 32.832 \\
\hline 18 & 0.15 & 34.455 & 34.441 & 34.424 & 34.409 & 34.369 \\
\hline 19 & 0.1 & 36.763 & 36.536 & 36.411 & 36.305 & 36.279 \\
\hline 20 & 0.05 & 39.824 & 39.614 & 39.437 & 39.237 & 39.205 \\
\hline
\end{tabular}




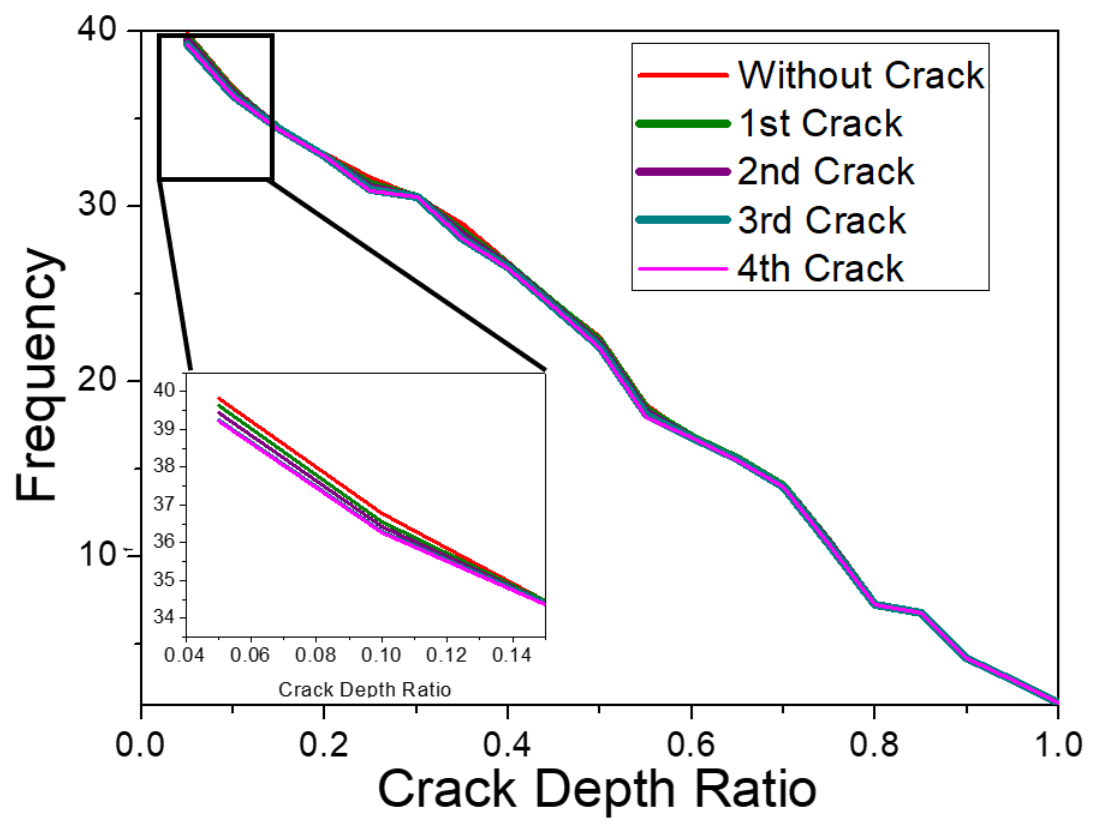

Figure 4. Plot between crack depth ratio and natural frequency for different crack locations. The insert image provides a zoomed-in view for the better comparison.

Table 4 enlists the damage index (DI) for each crack element of the crack location. The DI is the extent of damage which has been calculated from MAC by comparing reference tuned model with the mistuned model as explained before in Figure 3. It can be observed from the MAC severity results that DI for the very first element at first location (0.94) is 0.8304 with stiffness value of $5000 \mathrm{~N} / \mathrm{mm} 2$ and crack depth of 0.0799 , which is less than any other crack throughout the model. It is worth mentioning that the crack at third location gives different results because of large number of nodes and largest crack depth value.

Table 4. Smeared crack model testing for different crack locations.

\begin{tabular}{|c|c|c|c|c|c|}
\hline \multicolumn{2}{|c|}{ Model Name } & \multicolumn{2}{c|}{ Turbo fan Blade } & Units \\
\hline Modulus of Elasticity & E (MAT \# 1) & \multicolumn{3}{|c|}{ 2E +05} & $\mathrm{~N} / \mathrm{mm}^{2}$ \\
\hline Poison's Ratio & $V$ & \multicolumn{3}{|c|}{0.3} \\
\hline Density & $P$ & 0.94 & 0.67 & 0.32 & 0.1 \\
\hline Crack Locations & $b / l$ & 0.4102 & 0.5870 & 0.7029 & 0.4967 \\
\hline Crack Depth Ratio & a/d & 14 & 14 & 14 & 14 \\
\hline Elements under Crack & number of Elements & & & & 14 \\
\hline
\end{tabular}




\begin{tabular}{|c|c|c|c|c|c|c|c|c|c|}
\hline \multirow{2}{*}{$\begin{array}{l}\text { Element } \\
\text { Number }\end{array}$} & \multirow{2}{*}{$\begin{array}{c}\text { 'E', } \\
\mathrm{N} / \mathrm{mm}^{2}\end{array}$} & \multicolumn{2}{|c|}{ 1st Location } & \multicolumn{2}{|c|}{ 2nd Location } & \multicolumn{2}{|c|}{ 3rd Location } & \multicolumn{2}{|c|}{ 4th Location } \\
\hline & & $\begin{array}{l}\text { Crack } \\
\text { Depth }\end{array}$ & $\begin{array}{l}\text { Damage } \\
\text { Index }\end{array}$ & $\begin{array}{l}\text { Crack } \\
\text { Depth }\end{array}$ & $\begin{array}{l}\text { Damage } \\
\text { Index }\end{array}$ & $\begin{array}{l}\text { Crack } \\
\text { Depth }\end{array}$ & $\begin{array}{l}\text { Damage } \\
\text { Index }\end{array}$ & $\begin{array}{l}\text { Crack } \\
\text { Depth }\end{array}$ & $\begin{array}{l}\text { Damage } \\
\text { Index }\end{array}$ \\
\hline $\begin{array}{c}1 \text { st } \\
\text { Element }\end{array}$ & 5000 & 0.0799 & 0.8303 & 0.0941 & 1.8558 & 0.1404 & 1.9533 & 0.0655 & 2.7184 \\
\hline $\begin{array}{l}\text { 2nd } \\
\text { Element }\end{array}$ & 10000 & 0.1175 & 1.1088 & 0.1458 & 1.9866 & 0.1866 & 2.3905 & 0.1070 & 2.7340 \\
\hline $\begin{array}{c}\text { 3rd } \\
\text { Element }\end{array}$ & 25000 & 0.1403 & 1.3463 & 0.1901 & 2.0522 & 0.2636 & 2.7219 & 0.1342 & 2.7481 \\
\hline $\begin{array}{l}\text { 4th } \\
\text { Element }\end{array}$ & 50000 & 0.1746 & 1.3912 & 0.2477 & 2.0512 & 0.3030 & 2.6906 & 0.1738 & 2.7584 \\
\hline $\begin{array}{l}5 \text { th } \\
\text { Element }\end{array}$ & 75000 & 0.1949 & 1.4291 & 0.2660 & 2.0598 & 0.2865 & 2.6943 & 0.2009 & 2.7673 \\
\hline $\begin{array}{l}\text { 6th } \\
\text { Element }\end{array}$ & 100000 & 0.2327 & 1.4459 & 0.3147 & 2.0613 & 0.3669 & 2.7000 & 0.2347 & 2.7712 \\
\hline $\begin{array}{l}\text { 7th } \\
\text { Element }\end{array}$ & 115000 & 0.2463 & 1.4592 & 0.3376 & 2.0612 & 0.3724 & 2.7012 & 0.2671 & 2.7736 \\
\hline $\begin{array}{l}\text { 8th } \\
\text { Element }\end{array}$ & 130000 & 0.2844 & 1.4700 & 0.3755 & 2.0607 & 0.4342 & 2.7011 & 0.3098 & 2.7759 \\
\hline $\begin{array}{l}\text { 9th } \\
\text { Element }\end{array}$ & 145000 & 0.2940 & 1.4810 & 0.3951 & 2.0609 & 0.4442 & 2.7009 & 0.3354 & 2.7770 \\
\hline $\begin{array}{l}10 \text { th } \\
\text { Element }\end{array}$ & 160000 & 0.3308 & 1.4878 & 0.4386 & 2.0605 & 0.5072 & 2.7007 & 0.3801 & 2.7779 \\
\hline $\begin{array}{l}11 \text { th } \\
\text { Element }\end{array}$ & 175000 & 0.3392 & 1.4929 & 0.4447 & 2.0606 & 0.5145 & 2.7007 & 0.3993 & 2.7782 \\
\hline $\begin{array}{l}12 \text { th } \\
\text { Element }\end{array}$ & 190000 & 0.3751 & 1.4943 & 0.5109 & 2.0602 & 0.5739 & 2.7008 & 0.4348 & 2.7784 \\
\hline $\begin{array}{l}\text { 13th } \\
\text { Element }\end{array}$ & 195000 & 0.3809 & 1.4951 & 0.5092 & 2.0601 & 0.6202 & 2.7009 & 0.4679 & 2.7784 \\
\hline $\begin{array}{l}\text { 14th } \\
\text { Element }\end{array}$ & 200000 & 0.4102 & 1.4951 & 0.5870 & 2.0601 & 0.7029 & 2.7008 & 0.4967 & 2.7784 \\
\hline
\end{tabular}

Figure 5 presents the graphical presentation of Table 5. It shows that, at first location, 1st crack element is contributing to DI of 0.8303 , and the last element is ending up with DI of 1.4951 . For the second location, 1st crack element is preceded by DI of 1.4951 and results in DI of 1.8558. The accumulative DI for the second location is 2.0601. For third location, 1st crack element is again preceded by second location last element damage index, but it is showing a reduction in damage index 1.9533 that is due to the large element size of 0.1404 . This large element is surrounded by many parent elements that is why a reduction in damage index is pertinent regardless of the fact that it is the first element in the 3rd location. Third location damage index is summarized with a total value of 2.7008 and apprehended to 2.7184 by fourth location 1st element. All 56 elements end up with a total damage index of 2.7784 at the fourth crack location. The second crack element at first location has MAC severity value of 1.1088, then 1.3464 for 3rd and 1.3913 for 4th crack element, with the increase in value of stiffness reaching $50000 \mathrm{~N} / \mathrm{mm} 2$ and the crack depth ratio rising to 0.1746 , respectively. After that, the MAC severity graph tends to linear behavior, 
and there is no nominal jump or change in its values as shown in Figure 5. This same behavior is noticed for all four locations, indicating that there is a significant growth in the graph for the first three crack elements after it tends to smooth behavior as crack depth grows and stiffness value meets the parent element value.

A jump in the graph is noticed at the start of second location crack as it is also very close to the tip of the blade. First location crack ends up with a total damage index of 1.4952, with 2 nd location crack being 0.565 , 3rd location being 0.6408 , and 4th location being 0.0776 as shown in Figure 5 .

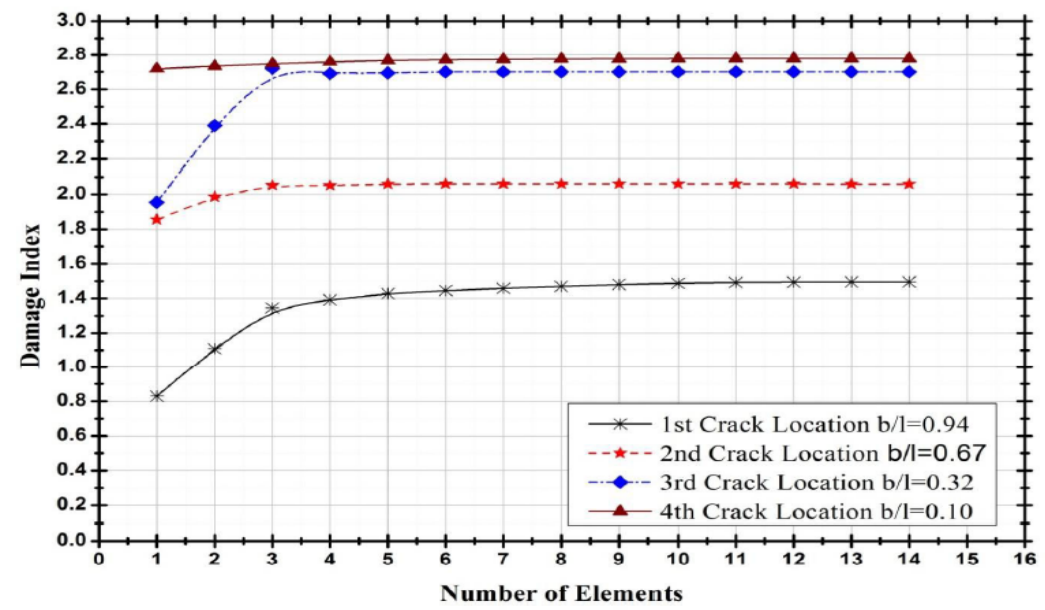

Figure 5. MAC severity graph for each crack element of all crack locations.
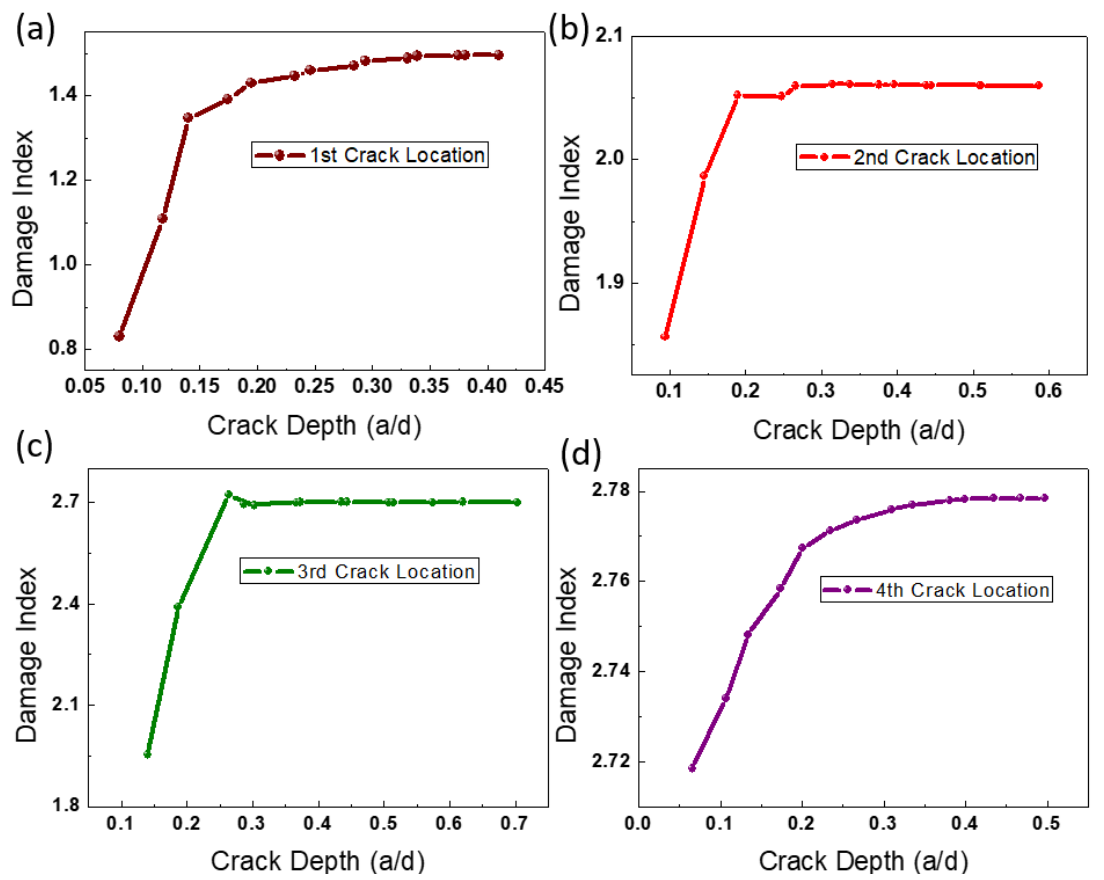

Figure 6. Graph between crack depth and damage index for the four crack locations. (a) $1^{\text {st }}$ crack location $\mathrm{b} / \mathrm{l}=0.94$, (b) $2^{\text {nd }}$ crack location $\mathrm{b} / \mathrm{l}=0.67$, (c) $3^{\text {rd }}$ crack location $\mathrm{b} / \mathrm{l}=0.32$, and (d) $4^{\text {th }}$ crack location $\mathrm{b} / \mathrm{l}=0.10$. 
The crack depth ratio is also affecting the damage index as it is noticed that the value of damage index is lower for larger crack depth ratios because of greater number of nodal elements and interconnecting elements. The crack depth ratio for first location crack is 0.4102 , 2nd location crack is 0.5870 , 3rd location crack is 0.7029 , and 4 th location crack is 0.4967 . The DI at the stem of the blade is the least effective because of the finer mesh elements and neighboring constraints elements of the blisk as shown in Figure 6. However, the behavior of the crack remains nonlinear throughout the crack length because of implementation of smeared material properties in the structure. Finally, in order to check the relationship of young's modulus of elements with DI, the changing pattern of ' $E$ ' has been kept the same for each crack location as shown in Figure 7. The value of ' $\mathrm{E}$ ' is increasing to the highest value of $200000 \mathrm{~N} / \mathrm{mm} 2$, as CDR approaching the parent material. It can be deduced from the figure that the contribution of ' $\mathrm{E}$ ' has very significant role to 1st three crack elements, and, afterwards, it approaches the properties of parent material.

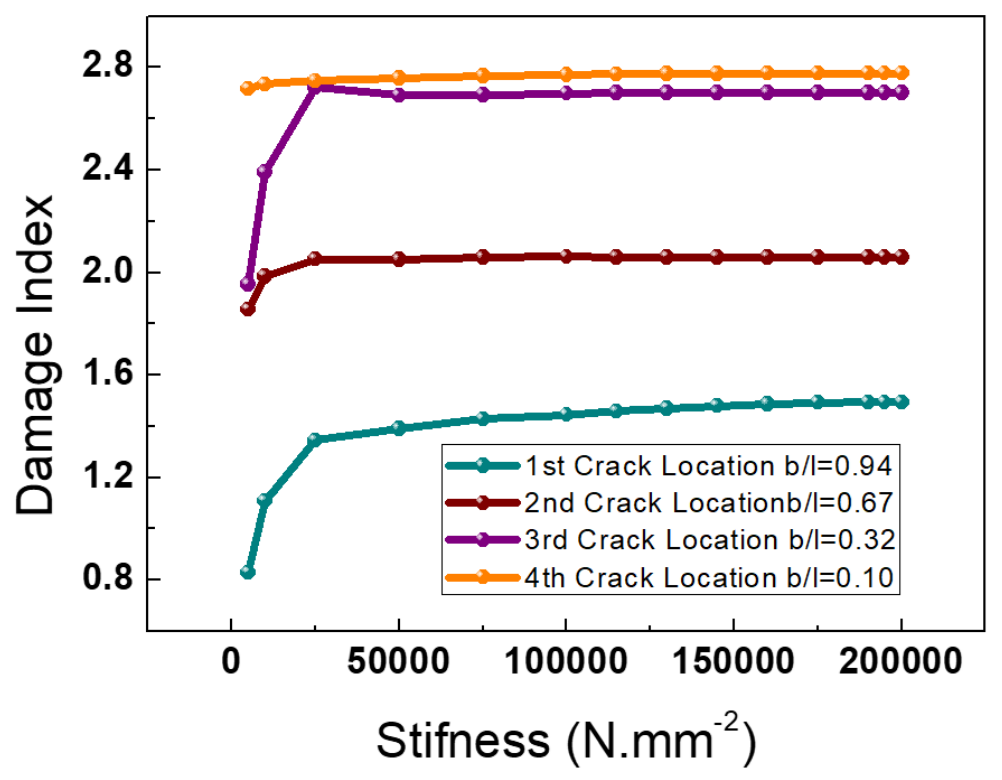

Figure 7. Graph between stiffness \& damage index for all four crack locations.

\section{CONCLUSIONS}

In this research work, an investigation on the effects of mistuning is performed for a fan blisk model by introducing variable depth cracks at four different locations of the blisk. It was found that the mistuning alters the vibrational characteristics of the structure and hence changes the dynamic response of the structure. For crack formations in the model, ANSYS mechanical APDL software is used for modeling the blisk, and MAC technique has been used for calculation of DI for each crack location. It was found that the first crack element contributes the most in damage index as compared to any other crack element throughout the width of the blade. Bearing the fact that value of $\mathrm{E}$ is the lowest as compared to the parent material at the first position, the first crack element always has the highest part of contribution to crack propagation. Regardless of the DI results, that are negligible after 1/4th depth of the crack, all four crack locations sum up a total damage index of 2.778 , which is not ignorable and causes catastrophic failure in the structure.

It is worth noting that the crack near the blade tip undergoes a larger DI as compared to any other crack location, because it suffers from large pressure difference. The stem of the blade is the least effective area because 
the elements at this location are under the effect of constraint elements. The damage index decreases as the material meets its parent material stiffness value, and DI is lower for larger crack elements because of larger numbers of interconnecting elements and nodal elements. Some more results are concluded about the severity of damage index, that is, DI of 0.665 and 0.747 that have been found at the blade tip and $(3 / 4)^{\text {th }}$ length of the blade, respectively, which are more crucial in terms of failure. The cracks on other locations don't contribute to a significant effect in the structure.

The research highlights the critical locations in the structures, critical size of crack element, and the effect of surrounding elements in the form of tabular data, graphs, and MAC Diagrams. The research distinguishes from the existing works in terms of data points acquired from the modal by selecting the variable elasticity, changing locations, targeting a maximum depth, comparing the results with respect to the locations and variables, and drawing conclusions to reach an effective result.

\section{REFERENCES}

Abboud, D, M Elbadaoui, and $\mathbf{N}$ Tableau. 2021. "Blade Monitoring in Turbomachines Using Strain Measurements." In Advances in Condition Monitoring and Structural Health Monitoring, 87-96. Springer.

Altunışık, Ahmet Can, Fatih Yesevi Okur, Sebahat Karaca, and Volkan Kahya. 2019. "Vibration-Based Damage Detection in Beam Structures with Multiple Cracks: Modal Curvature vs. Modal Flexibility Methods." Nondestructive Testing and Evaluation 34 (1): 33-53.

Anandan, Sivakumar. 2019. "Effect of Steel Fibre Profile on the Fracture Characteristics of Steel Fibre Reinforced Concrete Beams." Journal of Engineering Research 7 (2).

Beck, Joseph A, Jeffrey M Brown, Charles J Cross, and Joseph C Slater. 2014. "Component-Mode Reduced-Order Models for Geometric Mistuning of Integrally Bladed Rotors.” AIAA Journal 52 (7): 134556.

Booysen, Christopher, Philippus Stephanus Heyns, Michael Philip Hindley, and Ronnie Scheepers. 2015. "Fatigue Life Assessment of a Low Pressure Steam Turbine Blade during Transient Resonant Conditions Using a Probabilistic Approach.” International Journal of Fatigue 73: 17-26.

Bouzid, Omar Mabrok, Gui Yun Tian, Kanapathippillai Cumanan, and David Moore. 2015. "Structural Health Monitoring of Wind Turbine Blades: Acoustic Source Localization Using Wireless Sensor Networks." Journal of Sensors 2015.

Carminati, M, and S Ricci. 2018. "Structural Damage Detection Using Nonlinear Vibrations." International Journal of Aerospace Engineering 2018.

Dréau, Juliette, Benoit Magnain, Florence Nyssen, and Alain Batailly. 2021. "Polynomial Chaos Expansion for Permutation and Cyclic Permutation Invariant Systems: Application to Mistuned Bladed Disks.” Journal of Sound and Vibration 503: 116103.

ERBAYRAK, Engin, and Seda Erbayrak. 2020. "Determination of the Impact Damage Threshold Point of the Composite Material Usıng Fuzzy-Based Taguchi Method.” Journal of Engineering Research 8 (3).

Figaschewsky, Felix, and Arnold Kühhorn. 2015. "Analysis of Mistuned Blade Vibrations Based on Normally Distributed Blade Individual Natural Frequencies.” In ASME Turbo Expo 2015: Turbine Technical Conference and Exposition. American Society of Mechanical Engineers Digital Collection.

Francis, D. 2013. "Non-Destructive Evaluation (NDE) of Composites: Introduction to Shearography." In NonDestructive Evaluation (NDE) of Polymer Matrix Composites, 56-83. Elsevier.

Mehboob, S, Q U Zaman Khan, and S Ahmad. 2020. "Numerical Study for Evaluation of a Vibration Based 
Damage Index for Effective Damage Detection.” Bulletin of the Polish Academy of Sciences: Technical Sciences, 1443-56.

Nacim, Mellel, Ouali Mohammed, Dougdag Mourad, and Mohamedi Brahim. 2015. "Experimental Damage Localization in Beam by Using Natural Frequency Distribution and Modal Strain Energy Change Ratio Based Methods.” Journal of Vibroengineering 17 (3): 1203-17.

Rehman, A U, J A Rongong, and K Worden. 2010. "Crack Detection in Mistuned Repeating Structures." Proceedings of the ISMA 2010, Sep. 20-22, 2010, Leuven, Belgium.

Rehman, A U, K Worden, and J A Rongong. 2011. "Experimental Investigation of the MAC Based Crack Detection Technique for Repeating Structures.” In Istanbul: Proceedings of 4th IOMAC Conference.

Rehman, Anees U, Keith Worden, and Jem A Rongong. 2016. "On Crack Detection in Tuned and Mistuned Repeating Structures Using the Modal Assurance Criterion.” Strain 52 (3): 175-85.

Repetckii, O, I Ryzhikov, and Tien Quyet Nguyen. 2018. "Investigation of Mistuning Impact on Vibration of Rotor Bladed Disks.” In Journal of Physics: Conference Series, 944:12097. IOP Publishing.

Schwerdt, Lukas, Lars Panning-von Scheidt, and Jörg Wallaschek. 2021. "A Model Reduction Method for Bladed Disks With Large Geometric Mistuning Using a Partially Reduced Intermediate System Model." Journal of Engineering for Gas Turbines and Power 143 (7): 71031.

Thulasendra, G, and U K Dewangan. 2017. "Comparative Study of Vibration Based Damage Detection Methodologies for Structural Health Monitoring." International Journal of Civil Engineering and Technology 8 (7): 846-57.

Wang, Qiang, Yongquan Hu, Jinzhou Zhao, and Lan Ren. 2019. “A Numerical Model to Simulate Fracture Network Induced by Hydraulic Fracturing for 3D Shale Gas Reservoir with Geo-Stress Interference." Journal of Engineering Research 7 (2).

Yule, Lawrence, Bahareh Zaghari, Nicholas Harris, and Martyn Hill. 2021. "Surface Temperature Condition Monitoring Methods for Aerospace Turbomachinery: Exploring the Use of Ultrasonic Guided Waves." Measurement Science and Technology 32 (5): 52002.

Zeidan, Zaki, Ashraf A A Beshr, and Sara Sameh. 2020. "Structural Damage Detection of Elevated Circular Water Tank and Its Supporting System Using Geodetic Techniques" 69 (No 1): 117-40. http://journals.pan.pl/Content/114487/PDF/art_09.pdf.

Zhong, Hai, and Mijia Yang. 2016. "Damage Detection for Plate-like Structures Using Generalized Curvature Mode Shape Method." Journal of Civil Structural Health Monitoring 6 (1): 141-52. 